УДК 316.334.5:159.923.2

\title{
ФОРМИРОВАНИЕ ЭКОЛОГИЧЕСКОГО САМОСОЗНАНИЯ: ЦЕННОСТЬ ОПЫТА СТРАН ОЭСР ДЛЯ СОВРЕМЕННОЙ РОССИИ
}

\author{
Недоспасова Ольга Павловна, \\ olgaeconomy@mail.ru \\ Кайда Анастасия Юрьевна, \\ anastasiakaida@gmail.com \\ Ефремова Екатерина Александровна, \\ kat.efremovaa.98@gmail.com \\ Кузнецов Алексей Андреевич, \\ alex_k_ru@mail.ru
}

Национальный исследовательский Томский политехнический университет, Россия, 634050, г. Томск, пр. Ленина, 30

\begin{abstract}
Недоспасова Ольга Павловна, доктор экономических наук, профессор Школы инженерного предпринимательства Национального исследовательского Томского политехнического университета.
\end{abstract}

Кайда Анастасия Юрьевна, аспирант Инженерной школы информационных технологий и робототехники Национального исследовательского Томского политехнического университета.

Ефремова Екатерина Александровна, студент Алтайского филиала Финансового университета при Правительстве РФ.

Кузнецов Алексей Андреевич, магистрант Школы инженерного предпринимательства Национального исследовательского Томского политехнического университета.

Актуальность исследования подтверждается высоким потенциалом результативности подхода к решению экологических проблем на основе объединения усилий государства, бизнес-сообщества и граждан. Если в странах ОЭСР давно уделяется пристальное внимание данному подходу, то в России инициативы такого рода набирают силу только в последние годы. Предметом исследования является влияние уровня образования и возраста человека на степень выраженности его экологического самосознания. Объектом исследования выступают результаты международных исследований и социологического опроса, а также лучшие практики, ориентированные на повышение экологического самосознания граждан. Цель исследования заключается в выявлении ключевых факторов, определяющих уровень экологического самосознания населения в контексте перспектив их применения в России. Методы: анализ статистических данных, сравнительные оценки, социологический опрос, неструктурированное интервью с представителями российского экологически ориентированного бизнес-сообщества. Результаты: проведено сравнение влияния уровня образования и возраста на экологическое самосознание граждан ОЭСР, выявлены межстрановые различия в данных оценках, по результатам социологического исследования определено влияние уровня образования и возраста респондентов на экологическое самосознание граждан в нашей стране, осмыслены актуальные корпоративные инициативы по формированию экологического самосознания, сделаны выводы о перспективах их развития в России.

Ключевые слова: Экологическое самосознание, уровень образования, население, факторы, анализ, экологическая культура. 


\section{Введение}

Вопросы защиты окружающей среды в последние годы являются центральным элементом повестки дня любой страны мира $[1,2]$. Как известно, за последние 150 лет человечество пережило беспрецедентный рывок в промышленном и технологическом развитии, совпавший с еще одной важной глобальной тенденцией: ростом численности и средней продолжительности жизни населения планеты [3]. В таких условиях мировая экосистема подвергается все возрастающему давлению [4], а в научном сообществе преобладающим становятся мнение о ее «хрупкости» и угрозе необратимой экологической катастрофы в глобальном масштабе $[5,6]$. В таких условиях все более четко осознается важность как общественного, так и личного внимания к широкому спектру экологических проблем, обусловленных экономической активностью человека: ухудшению качества воздуха, питьевой воды, загрязнению почвы и вод мирового океана, утрате природного разнообразия и т. д. [7].

В настоящее время доступны результаты национальных и международных исследований, нацеленных на поиск эффективных мер повышения экологического самосознания граждан, выявление и анализ факторов, влияющих на формирование экологического типа мышления и объясняющих причины и последствия безответственного отношения людей к окружающей среде [8-10]. Это не случайно. Для современного мира все более характерно осознание важности объединения ответственности за сохранение природы государства, представителей бизнес-сообщества и граждан, сочетание их усилий для решения актуальных экологических проблем, сохранения природы для будущих поколений.

Если в странах ОЭСР данной теме уделяется пристальное внимание давно, то в России данное направление активно набирает силу только в последние годы. Как известно, озабоченность общества и государства ухудшением состояния окружающей среды, обусловила проведение в РФ в 2017 г. «года экологии», дала старт т. н. «мусорной реформе», стала стимулом для начала множества экологических проектов как волонтёрского, так и бизнес-формата.

В связи с этим изучение международного опыта формирования экологического самосознания граждан и факторов, влияющих на него, является для нашей страны крайне важным. Особого внимания в этом отношении заслуживает изучение результатов исследований, проводимых экспертами Организации экономического сотрудничества и развития (ОЭСР). Так, в 2018 г. один из разделов ежегодного обзора ОЭСР «Education at a Glance» [11] был посвящен оценке влияния уровня образования и возраста респондентов стран, входящих в данную организацию и стран ее партнеров, на экологическое самосознание людей, их обеспокоенность ключевыми экологическими проблемами современности и готовность к активным действиям для улучшения ситуации.

Необходимость учета мирового опыта для объединения активности граждан, общественных организаций, государственных институтов для решения актуальных для нашей страны экологических проблем не вызывает сомнения. Данное обстоятельство определило актуальность данного исследования, целью которого является выявление и анализ ключевых факторов, определяющих уровень экологического самосознания человека в контексте исследования перспектив их развития в отечественной практике.

\section{Взаимосвязь между уровнем образования, возрастом и степенью выраженности экологического самосознание человека: сравнительные оценки для стран ОЭСР}

Сторонники теории человеческого капитала убедительно доказали, что образование влечет за собой мощные социально-экономические экстерналии, важные как для 
индивида, так и для общества в целом [12]. Важно отметить, что образование дает людям не только лучшие возможности для роста доходов, самореализации, увеличивает продолжительность жизни [13], но и позволяет человеку критически оценивать свое поведение, вносить в него важные коррективы [14]. Благодаря росту уровня образования общество оказывается более подготовленным к достижению ключевых целей устойчивого развития, в том числе к социальным, экономическим и политическим изменениям для защиты окружающей среды [15]. Однако степень выраженности экологического самосознания у людей, имеющих различный уровень образования, а также относящихся к различным возрастным группам, имеет существенные различия, в том числе межстрановые. В указанном исследовании эксперты ОЭСР анализировали влияние уровня образования и частично возраста на степень выраженности экологического самосознания респондентов, делая акцент на четыре аспекта данного явления:

1) осведомленность об экологических проблемах;

2) признание экологических проблем;

3) отношение к проблемам окружающей среды;

4) действия в ответ на экологические проблемы.

Рассмотрим основное содержание данных аспектов более подробно.

Осведомленность об экологических проблемах рассматривалась исследователями с точки зрения знания человеком определенных фактов, касающихся той или иной экологической ситуации, понимания обстоятельств ее возникновения и возможных последствий. Этот аспект экологического самосознания был заведомо определён как «пассивный», т. е. не предполагающий каких-либо действий респондентов для улучшения экологической ситуации.

Признание экологических проблем оценивалось экспертами с точки зрения способности человека принять определённое положение дел в области экологии за «норму» и на основе интерпретации доступных фактов оценивать наличие и масштаб неблагоприятных для экологии отклонений от этой нормы.

Отношение к проблемам окружающей среды анализировалось с точки зрения эмоциональных и нравственных оценочных суждений человека об окружающей среде, основанных на его системе ценностей.

Действия в ответ на экологические проблемы рассматривались как выражение убеждений человека, проявляющееся при осуществлении им определенных видов активности, побудительным мотивом к которым является желание изменить ту или иную экологическую ситуацию в лучшую сторону.

Анализ результатов, представленных в рассматриваемом обзоре, показал, что самый высокий уровень осведомленности об экологических проблемах оказался в странах ОЭСР и в странах-партнерах этой организации у 15-летних подростков. Они заметно превзошли по этому параметру респондентов более старших возрастных групп (в которые входили граждане трудоспособного возраста в возрасте от 25 лет до 64 лет). Это, безусловно, делает честь современной системе школьного образования в анализируемых странах, отражает способность национальных систем образования формировать важные для современного мира экологические знания. Как выяснилось, старшеклассники очень хорошо осведомлены прежде всего об экологических проблемах, связанных с использованием природных ресурсов (исчезновением растений и животных, уничтожением лесов, нехваткой воды и т. д). В среднем не менее $70 \%$ подростков стран ОЭСР и стран-партнеров сообщили, что хотя бы немного знают об этих проблемах и могут объяснить их в общих чертах. Лидерами в осведомленности об угрозе вырубки лесов стали ребята из России (89\%), Польши (86 \%) и Латвии (86\%). Менее все- 
го, однако, тоже на довольно высоком уровне, подростки знают об этой проблеме в Швеции (51 \%), Южной Корее (52 \%) и Греции (59 \%). Больше всего о проблемах, связанных с загрязнением воздуха, знают подростки из Португалии (91 \%), Словении $(91 \%)$, Греции (90 \%) и Финляндии (90\%). Наименее (тем не менее весьма хорошо) осведомлены об этой проблеме ребята из Нидерландов (61 \%), Японии (71 \%) и Новой Зеландии (73 \%). Для России данный показатель также весьма высок и составляет $89 \%$. Наиболее осведомлены о проблеме нехватки питьевой воды подростки из Португалии $(88 \%)$, Южной Кореи $(86 \%)$ и Словении (85\%). Наименее - в Японии (45\%), России $(54 \%)$, Новой Зеландии (54 \%) и Франции (58 \%).

Заслуживает внимания тот факт, что уровень осведомленности старшеклассников об экологических проблемах техногенного характера (увеличении количества парниковых газов в атмосфере, накоплении ядерных отходов и использовании генетически модифицированных продуктов) оказался значительно ниже. Лидерами по осведомленности об угрозе увеличения уровня парникового газа в атмосфере стали подростки из Португалии (86 \%), Швеции (81 \%) и Великобритании (80\%). Менее всего об этой проблеме оказались осведомлены подростки из Израиля (46\%), Латвии (48\%) и Чехии (50 \%). Для России данный показатель равен 57 \%. Лидерами по осведомленности об угрозе накопления ядерных отходов стали молодые люди из России (71 \%), Турции (69 \%), Португалии (67 \%) и Финляндия (66 \%), а самые низкие значения осведомленности этими проблемами показали подростки из Новой Зеландии (39 \%), Японии (36 \%) и Израиля (35\%). Самую высокую осведомленность об угрозе применения ГМО показали старшеклассники из Словении (74\%), Турции (70\%) и Франции (61 \%), самые низкие показатели - у подростков из Чехии (19\%), Нидерландов (20\%) и Венгрии (23\%). Для России данный показатель равен $57 \%$.

Однако более высокие, чем у взрослых респондентов, показатели осведомленности об экологических проблемах современного общества у подростков не стали решающим условием их высокой личной экологической активности, ярко выраженного стремления внести свой вклад в решение экологических проблем. Взрослые респонденты стран ОЭСР и стран-партнеров при более низких, чем у подростков показателях осведомленности об экологических проблемах, продемонстрировали более высокий уровень их признания (второй аспект), более осознанное отношение к проблемам окружающей среды (третий аспект), а также более высокую личную активность в ответ на экологические проблемы (четвертый аспект). Исходя из цели данной работы, крайне важно отметить и то, что степень вовлеченности взрослых граждан в экологическую проблематику в целом практически в каждой стране возрастала по мере повышения уровня образования респондентов.

Уверенность взрослого населения ОЭСР и стран-партнеров во влиянии экологических проблем на их повседневную жизнь (второй аспект) заметно повышалась практически в каждой стране по мере роста уровня образования респондентов. Эти значения для всей совокупности стран оказались диапазоне от 58 до 96 \% (табл. 1). Максимальную долю взрослых, уверенных в том, что экологические проблемы влияют на их повседневную жизнь (по всем уровням образования), продемонстрировала Греция, минимальную - Латвия (для граждан с низким уровнем образования) и Австрия (для граждан со средним и высшим образованием).

Оценивая долю взрослых, уверенных в важности личной ответственности за состояние окружающей среды (третий аспект), эксперты получили в целом более низкие оценки, чем при оценивании влияния экологических проблем на повседневную жизнь человека. Однако они оказались весьма схожими (табл. 2). В целом данные зна- 
чения в анализируемых странах были в диапазоне от 43 до $89 \%$, и они также имели тенденцию к повышению по мере роста уровня образования респондентов (за исключением Израиля, Норвегии, Польши, России и Швейцарии, где эта зависимость не проявилась или не была устойчивой).

Таблица 1. Доля (в процентах) взрослого населения (25-64 лет), уверенного в том, что экологические проблемы влияют на повседневную жизнь, по уровням образования

Table 1. Percentage of adults (25-64 year-olds) who agree that environmental issues have an impact on their daily life by educational attainment

\begin{tabular}{|c|c|c|c|}
\hline \multirow[b]{2}{*}{$\begin{array}{l}\text { Страна } \\
\text { Country }\end{array}$} & \multicolumn{3}{|c|}{ Уровень образования/Educational attainment } \\
\hline & $\begin{array}{c}\text { Начальное или } \\
\text { неполное среднее } \\
\text { Below upper } \\
\text { secondary }\end{array}$ & $\begin{array}{l}\text { Среднее и среднее } \\
\text { профессиональное } \\
\text { Upper secondary or post- } \\
\text { secondary non-tertiary }\end{array}$ & Высшеe/Tertiary \\
\hline Австрия/Austria & 70 & $66 \mathrm{~min}$ & $73 \mathrm{~min}$ \\
\hline Бельгия/Belgium & 66 & 67 & 78 \\
\hline Чехия/Czech Republic & 77 & 78 & 75 \\
\hline Эстония/Estonia & 78 & 78 & 81 \\
\hline Финляндия/Finland & 79 & 77 & 76 \\
\hline Греция/Greece & $93 \max$ & $95 \max$ & $96 \max$ \\
\hline Венгрия/Hungary & 73 & 80 & 86 \\
\hline Ирландия/Ireland & 80 & 80 & 85 \\
\hline Латвия/Latvia & $58 \mathrm{~min}$ & 79 & 79 \\
\hline Люксембург/Luxembourg & 75 & 78 & 89 \\
\hline Польша/Poland & 81 & 80 & 76 \\
\hline Словакия/Slovak Republic & 76 & 85 & 83 \\
\hline Словения/Slovenia & 86 & 88 & 88 \\
\hline Испания/Spain & 85 & 89 & 91 \\
\hline Великобритания/United Kingdom & 81 & 78 & 90 \\
\hline Литва/Lithuania & 75 & 87 & 90 \\
\hline Среднее/Average & 77 & 80 & 83 \\
\hline
\end{tabular}

Таблища 2. Доля (в процентах) взрослого населения (25-64 лет), уверенного в важности личной ответственности за состояние окружающей среды, по уровням образования

Table 2. Percentage of adults (25-64 year-olds) who believe in personal responsibility for looking after the environment, by educational attainment

\begin{tabular}{|l|c|c|c|}
\hline \multirow{2}{*}{ Страна/Country } & \multicolumn{3}{|c|}{ Уровень образования/Educational attainment } \\
\cline { 2 - 4 } & $\begin{array}{c}\text { Начальное или не- } \\
\text { полное среднеe } \\
\text { Below upper second- } \\
\text { ary }\end{array}$ & $\begin{array}{c}\text { Среднее или среднее про- } \\
\text { фессиональное } \\
\text { Upper secondary or post- } \\
\text { secondary non-tertiary }\end{array}$ & Bысшеe/Tertiary \\
\hline Австрия/Austria & 65 & 66 & 72 \\
\hline Бельгия/Belgium & 76 & 74 & 74 \\
\hline Великобритания/United Kingdom & 56 & 59 & 76 \\
\hline Германия/Germany & 70 & 72 & 59 \\
\hline Израиль/Israel & 68 & 62 & 68 \\
\hline Ирландия/Ireland & 61 & 61 & 70 \\
\hline Исландия/Iceland & 59 & 59 & 72 \\
\hline Нидерланды/Netherlands & 66 & 66 & \\
\hline
\end{tabular}




\begin{tabular}{|l|c|c|c|}
\hline Норвегия/Norway & 57 & $\mathbf{4 6} \mathbf{~ m i n}$ & $\mathbf{5 7} \mathbf{~ m i n}$ \\
\hline Польша/Poland & 74 & 80 & 77 \\
\hline Россия/Russian Federation & 65 & 68 & 65 \\
\hline Словения/Slovenia & $\mathbf{8 7 ~ \mathbf { m a x }}$ & $\mathbf{8 5 ~} \mathbf{m a x}$ & $\mathbf{8 9} \mathbf{~ m a x}$ \\
\hline Финляндия/Finland & 65 & 72 & 75 \\
\hline Франция/France & 63 & 63 & 64 \\
\hline Чехия/Сzech Republic & $\mathbf{4 3 ~ m i n}$ & 55 & 65 \\
\hline Швейцария/Switzerland & 84 & 78 & 75 \\
\hline Швеция/Sweden & 64 & 62 & 65 \\
\hline Эстония/Estonia & 70 & 72 & 76 \\
\hline
\end{tabular}

Интересно, что на вопрос о личных экологических действиях (четвертый acnект) в среднем утвердительно ответило не более 30 \% взрослого населения ОЭСР. В то же время именно здесь респонденты продемонстрировали наиболее значимые различия по уровням образования: чем выше уровень образования, тем выше степень личного участия человека в перечисленных действиях. Особенно это было заметно при сообщении респондентов о раздельном сборе мусора, экономии электроэнергии, снижении потребления и повторном использовании воды, покупке овощей и фруктов, выращенных без применения пестицидов и товаров, производимых без тестирования на животных. Обращает на себя внимание и тот факт, что различия по уровню образования у тех, кто подписывал экологические петиции и участвовал в соответствующих митингах были менее значимыми, чем по названным выше каждодневным видам личной экологической активности.

Таким образом, взрослые граждане ОЭСР и стран-партнеров продемонстрировали наличие важного и относительно мало изученного социального эффекта образования, состоящего в повышении уровня экологического самосознания человека по мере повышения его уровня. Важно отметить, что данный эффект проявляется скорее не в более полной осведомленности человека об экологических проблемах (что, как оказалось, характерно в основном для подростков), а в признании важности экологических проблем для обычной жизни человека, формировании четкой личной позиции в отношении той или иной проблемы, решимости к осуществлению конкретных и ежедневных действий для сохранения природы.

\section{Взаимосвязь между уровнем образования, возрастом и степенью выраженности экологического самосознание человека: выводы по итогам социологического опроса}

Данные выводы весьма актуальны для России. Учитывая то, что наша страна лишь частично участвует в международных проектах, инициируемых ОЭСР, авторами был проведен инициативный социологический опрос. Его целью была попытка выявить (по примеру стран-ОЭСР) или опровергнуть влияние уровня образования респондентов и их возраста на степень выраженности экологического самосознания. Кроме возраста и уровня образования в расчет также принималось несколько других параметров. Респондентов просили предоставить дополнительную информацию о себе (указать возраст, пол, уровень образования, место жительства). В опросе приняло участие 130 респондентов, рандомно распределенных по возрасту (от 15 до 55 лет) и регионам России: Москва, Московская область, Санкт-Петербург, Ленинградская область, Новосибирск, Волгоград, Геленджик, Алтайский край (города Бийск, Горно-Алтайск, Барнаул и Рубцовск), Томск и Томская область, в том числе г. Северск. В ходе опроса респондентам было предложено ответить на 18 вопросов, которые охватывали те же аспекты эколо- 
гического самосознания, которые анализировались экспертами ОЭСР (осведомленность об экологических проблемах, их признание, личное отношение к экологическим проблемам и участие в защите окружающей среды):

1. Вы посадили хотя бы одно дерево?

2. Вы следите, чтобы вода не текла без надобности и были исправны краны?

3. Вы используете энергосберегающие лампочки?

4. Вы выключаете свет, если он не нужен?

5. Вы итаете состав продуктов перед тем, как сделать покупку?

6. Вы используете переработанную бумагу?

7. Вы не распечатываете материалы, которые можно прочитать в электронном виде?

8. Вы выбираете спреи с пометкой «безопасно для озонового слоя» вместо аэрозолей?

9. Вы знаете, в чем опасность тестирования любых товаров на животных?

10. Вы отдаете предпочтение товарам с пометкой «Not tested on animals» («не тестировано на животных»)?

11. Вы жаловались когда-либо производителю на качество его товара?

12. Вы являетесь членом экологической организации или общества защиты животных?

13. Вы можете назвать животное или растение, находящееся на грани уничтожения (занесённых в Красную книгу)?

14. Вы не покупаете в магазинах пластиковые пакеты, предпочитая тряпичные сумки и пакеты из бумаги?

15. Вы отдаете предпочтение товарам с меньшим количеством упаковки?

16. Вы используете упаковку (пакеты и ёмкости) вторично, находите им новое полезное применение?

17. Вы сдаете в пункты приёма стекло, макулатуру или алюминий (бутылки, банки, бумагу)?

18. Вы не оставляете после себя мусор на пляже?

Важно отметить, что опрос проходил с использованием специально разработанной Google-формы, в которой его участники могли выбрать только два варианта ответа: «да» или «нет». Если ответ респондента отражал положительное влияние на окружающую среду, помогал ее защите, то за такой ответ участник опроса получал один балл. В противном случае (при ответе, отрицательно влияющем на экологию) балл не присуждался. По окончании опроса простым суммированием определялось общее количество баллов, набранных каждым из опрашиваемых. Полученные значения стали основой для ранжирования респондентов по степени выраженности у них экологического самосознания. Если участник опроса набирал минимальное количество баллов (0-4), то исследователи относили его к группе с низкой степенью выраженности экологического самосознания; при количестве набранных баллов в диапазоне от 5 до 9 - участники опроса были отнесены к среднему (удовлетворительному) уровню экологического самосознания; при наборе от 10 до 16 баллов - в группу с «хорошей» его выраженностью, а для тех, кто набирал 17 и 18 баллов, принималось решение о высоком уровне экологического самосознания.

Опрос показал, что самый высокий уровень экологического самосознания проявился у молодых респондентов: 17 и 18 баллов набрали лишь те опрашиваемые, возраст которых находится в диапазоне от 18 до 23 лет. Важно, что в эту возрастную группу вошли в основном участники с высшим образованием или те, кто получает его в настоящее время. Таким образом, социологический опрос показал результаты, которые в 
целом не противоречат выводам о взаимосвязи уровня экологического самосознания и образования человека, сделанным ранее для стран ОЭСР. Как и респонденты из стран, входящих в данную организацию, так и те образованные молодые люди, принявшие участие в нашем опросе, показали более высокую осведомлённость об основных экологических проблемах, выразили в своих ответах признание их значимости, проявили свое заинтересованное отношение к ним и готовность действовать для их преодоления.

Важно и то, что результаты опроса не выявили значимых гендерных отличий в уровне экологического самосознания: и юноши, и девушки с высшим и неоконченным высшим образованием показали примерно равную степень обеспокоенности экологическими проблемами (в среднем на уровне 10 баллов и выше). То же самое можно сказать и о месте проживания молодых респондентов: практически в любом из анализируемых регионов уровень экономического самосознания у молодежи с высоким уровнем образования был на уровне не ниже среднего.

Дополнительного внимания заслуживает оценка взаимосвязи уровня экологического самосознания и возраста опрашиваемых. Более взрослые респонденты (в возрасте 24 года и старше) так же, как и более молодые, проявляли весьма высокий уровень экологического самосознания. Они набрали в среднем от 10 до 16 баллов, при этом чаще, чем молодые участники опроса, сообщали о своём осознанном экологическом поведении в повседневных ситуациях (более высокая частота выбора «положительных» ответов на вопросы 5, 10, 15 и 16). Данный вывод является важным аргументом о перспективности расширения участия граждан среднего и старшего возраста в экологических проектах и инициативах в качестве экспертов, способных своим личным примером (в том числе на основе жизненного и (или) профессионального опыта) повлиять на экологическое самосознание детей и молодежи.

\section{Корпоративные практики, ориентированные на повышение экологического самосознания}

В последние годы стремительно растет количество личных и корпоративных инициатив, направленных на сохранение и защиту окружающей среды. Однако в данной работе было решено более подробно осмыслить только один пример корпоративной практики, которая осуществляется в Томске и непосредственно связана с формированием экологического самосознания у широкого круга стейкхолдеров. В ходе неструктурированного интервью с руководителем Томского регионального общественного экологического движения «Вангог» выяснилось, что данная организация ведет 12 экопроектов и имеет большой опыт проведения экологических мероприятий. Наиболее интересным и перспективным для успешного тиражирования можно считать проект «Офис EVI», главной задачей которого является формирование принципиально новой для г. Томска корпоративной культуры. Проект включает в себя обучение сотрудников сортировке отходов, установку эко-боксов в офисе, внедрение экологических принципов, в том числе размещение лейблов «EVI офис» и «Van and Gog» [16], которые позволяют идентифицировать компанию-участника данного проекта как экологически ответственный бизнес. Совокупность таких действий повышает уровень доверия партнеров и клиентов к производимым товарам, работам и услугам, формирует положительный имидж как компании, так и ее сотрудников в региональном социуме.

Осознанный отказ всех сотрудников компании от одноразовой пластиковой посуды во время кофе-брейков позволяет существенно сократить количество мусора, вывозимого на городские полигоны. При этом «Вангог» не демонстрирует избыточного экологического фанатизма, но настойчиво внедряет в бизнес-практику такие нововведе- 
ния, как замена люминесцентных ламп на светодиодное освещение, бутилированной воды на фильтры в системе водоснабжения, устанавливает сенсорные датчики на краны и пр.

Отметим, что работа офисов в эко-формате не только способствует решению важных экологических проблем, но и повышает уровень экологического самосознания ее сотрудников, а также обеспечивает компании весьма ощутимые экономические дивиденды: создает условия для роста ее ценности для собственников и инвесторов $[17,18]$. Кроме того, такие инициативы способствуют укреплению в трудовых коллективах горизонтальных и межпоколенческих связей, позволяют повысить вовлеченность работников разных возрастов в решение актуальных для регионального социума экологических проблем, обеспечивают рост их социальной активности, повышают востребованность жизненного опыта сотрудников старшего возраста для экологического самосознания их более молодых коллег $[19,20]$.

\section{Заключение}

Исследование показало наличие и значимость важной социальной экстерналии образования - повышения уровня экологического самосознания человека по мере повышения его уровня образования и возраста. Этот вывод подтвержден данными, представленными в международном отчете «Education at a Glance 2018: OECD Indicators». К аналогичным выводам авторы пришли при анализе результатов инициативного анкетирования, проведенного среди граждан РФ различного возраста и уровня образования, проживающих в различных регионах нашей страны. Важно, что и для стран-ОЭСР, и для опрошенных россиян характерны очень высокие оценки степени осведомленности о наиболее важных экологических проблемах преимущественно среди молодежи. Однако по мере повышения возраста опрашиваемых у респондентов с высоким уровнем образования становятся более высокими оценки по другим аспектам экологического самосознания: личному отношению к данным проблемам и активности человека для их решения. В связи с этим описанный в данной работе пример деятельности Томского регионального общественного экологического движения «Вангог» имеет широкие перспективы тиражирования. Данный проект направлен не только на решение актуальных экологических проблем, но и на развитие экологического сознания сотрудников. Он обеспечивает компании важные экономические и репутационные выгоды, способствует укреплению горизонтальных и межпоколенческих связей в региональном социуме.

Исследование выполнено по проекту РФФИ «Разработка комплексной оценки эффективности вовлеченности пожилых людей в региональный соииум», №19-010-00984.

\section{СПИСОК ЛИТЕРАТУРЫ}

1. Open Working Group proposal for Sustainable Development Goals. URL: https://sustainabledevelopment. un.org/focussdgs.html (дата обращения 25.02.2020).

2. The Global Risks Report 2018. 13th ed. - Geneva: World Economic Forum, 2018. URL: www3.weforum.org/docs/WEF_GRR18_Report.pdf (дата обращения 25.02.2020).

3. Шишкин В.В. Экологическое сознание общества - идеологическая основа новой экономики знаний // Экономика и предпринимательство. - 2019. - № 6. - С. 92-95.

4. Living Planet Report 2016: risk and resilience in a new era // WWF, 2016. URL: wwf.panda.org/ about_our_earth/all_publications/lpr_2016/ (дата обращения 25.02.2020).

5. Ripple W. et al. World scientists' warning to humanity: a second notice // BioScience. - 2017. - V. 67. № 12. - P. 1026-1028. URL: http://dx.doi.org/10.1093/biosci/bix125 (дата обращения 25.02.2020). 
6. Waters C. et al. The Anthropocene is functionally and stratigraphically distinct from the Holocene // Science. - 2016. - V. 351. - Iss. 6269. URL: https://science.sciencemag.org/content/351/6269/aad2622 (дата обращения 25.02.2020).

7. Туркулец С.Е., Туркулец А.В., Аникеева Н.С. Формирование экологического сознания в контексте развития национального самосознания россиян // Власть и управление на Востоке России. - 2017. № 1 (78). - C. 132-137.

8. Strumse E. The ecological self: a psychological perspective on anthropogenic environmental change // European Journal of Science and Theology. - 2007. - V. 3. - № 2. - P. 7-12.

9. Raus R. Student teacher ecological self in the context of education for sustainable development: a longitudinal case study // Journal of Education for Sustainable Development. - 2017. - № 11 (2). - P. 123-140. DOI: $10.1177 / 0973408218779283$

10. Мдивани М.О., Хисамбеев Ш.Р. Экологическое самосознание как основа проэкологического поведения // Азимут научных исследований: педагогика и психология. - 2017. - Т. 6. - № 4 (21). - С. 346-348.

11. Education at a Glance 2018: OECD Indicators. - 460 p. URL: https://www.oecdilibrary.org/education/education-at-a-glance-2018_eag-2018-en (дата обращения 25.02.2020).

12. Недоспасова О.П., Барышева Г.А., Кайда А.Ю. Социальные экстерналии образовательных инвестиций: опыт стран ОЭСР // Национальные интересы: приоритеты и безопасность. - 2019. - Т. 15. № 4 (373). - C. 629-647.

13. The Global Human Capital Report 2017. Preparing people for the future of work. URL: http://www3. weforum.org/docs/WEF_Global_Human_Capital_Report_2017.pdf (дата обращения 01.03.2020).

14. Иванкина Л.И., Латыговская Т.П. Социальное управление в условиях нестабильности современного мира. - Томск: STT, 2013. - $200 \mathrm{c}$.

15. Environment at a Glance 2020. URL: https://doi.org/10.1787/4ea7d35f-en (дата обращения: 01.03.2020).

16. Бронникова Е. С Ван Гогом без мусора: томский бизнесмен создал движение о разделении отходов. URL: https://tv2.today/News/S-van-gogom-bez-musora-tomskiy-biznesmen-organizuet-dvizhenie-o-razdeleniiothodov\#ixzz6GfV69bN2https://tv2.today/News/S-van-gogom-bez-musora-tomskiy-biznesmen-organizuetdvizhenie-o-razdelenii-othodov\#ixzz6E5hYNTXe (дата обращения 15.03.2020).

17. Амирова Н.Р., Саргина Л.В., Фролова А.С. Развитие экологического тренда на современном рынке товаров и услуг // ЦИТИСЭ. - 2019. - № 5. - С. 277-291.

18. Заболотнов А.Ю. Перспективы развития экологического самосознания в России // Экономика и социум. - 2015. - № 1-3 (14). - С. 138-142.

19. Активное благополучие старшего поколения: долголетие и вовлеченность в региональный социум / Г.А. Барышева, Е.И. Клемашева, В.А. Маланина, Е.А. Монастырный, О.П. Недоспасова, И.А. Павлова, Е.А. Фролова. - Томск: СТТ, 2019. -136 с.

20. Фролова Е.А., Кашапова Э.Р., Клемашева Е.И., Маланина В.А. Сравнительный анализ социальнодемографических характеристик пожилых людей в России // Векторы благополучия: экономика и социум. - 2019. - № 4 (35). - C. 54-62. URL: http://jwt.su/journal/article/view/995/1016 (дата обращения 01.03.2020).

Поступила 17.03.2020 2. 
UDC 316.334.5:159.923.2

\title{
FORMATION OF ECOLOGICAL SELF-CONSCIOUSNESS: VALUE OF EXPERIENCE OF OECD COUNTRIES FOR MODERN RUSSIA
}

\author{
Olga P. Nedospasova, \\ olgaeconomy@mail.ru \\ Anastasia Y. Kaida, \\ anastasiakaida@gmail.com \\ Ekaterina A. Efremova, \\ kat.efremovaa.98@gmail.com \\ Alexey A. Kuznetsov, \\ alex_k_ru@mail.ru \\ National Research Tomsk Polytechnic University, \\ 30, Lenin avenue, Tomsk, 634050, Russia
}

Olga P. Nedospasova, Dr. Sc., professor, National Research Tomsk Polytechnic University.

Anastasia Y. Kaida, postgraduate student, National Research Tomsk Polytechnic University.

Ekaterina A. Efremova, student, Altai branch of the Financial University of the Russian Federation Government.

Alexey A. Kuznetsov, master student, National Research Tomsk Polytechnic University.

The relevance of the study is confirmed by the high potential of the effectiveness of the approach to solving environmental problems by combining the efforts of the state, the business community and citizens. While in the OECD countries this approach has been given close attention for a very long time, in Russia initiatives of this kind are gaining strength only in recent years. The subject of the study is the influence of the level of education and age of a person on the severity of his/her environmental self-awareness. The object of the research is the results of international studies and a sociological survey, as well as best practices aimed at improving the environmental self-awareness of citizens. The purpose of the study is to identify key factors that determine the level of environmental self-awareness of the population in the context of the prospects for their application in Russia. Methods: analysis of statistical data, comparative estimates, a sociological survey, unstructured interviews with representatives of the Russian environmentally-oriented business community. Results. The influence of the level of education and age on the environmental self-awareness of OECD citizens is compared, cross-country differences in these assessments are identified, the results of a sociological study determine the impact of the level of education and age of respondents on the environmental self-awareness of citizens in our country, relevant corporate initiatives for the formation of environmental self-awareness are comprehended, conclusions are drawn about the prospects for their development in Russia.

Key words: Environmental identity, level of education, population, factors, analysis, ecological culture.

The study was supported by the Russian Foundation of Basic Research (project no. 19-010-00984).

\section{REFERENCES}

1. Open Working Group proposal for Sustainable Development Goals. Available at: https://sustainabledevelopment.un.org/focussdgs.html (accessed 25 February 2020).

2. The Global Risks Report 2018. $13^{\text {th }}$ ed. Geneva, World Economic Forum, 2018. Available at: www3.weforum.org/docs/WEF_GRR18_Report.pdf (accessed 25 February 2020). 
3. Shishkin V.V. Ekologicheskoe soznanie obshchestva - ideologicheskaya osnova novoy ekonomiki znaniy [The environmental consciousness of society - the ideological basis of the new knowledge economy]. Ekonomika i predprinimatelstvo, 2019, no. 6, pp. 92-95.

4. Living Planet Report 2016: risk and resilience in a new era. WWF, 2016. Available at: wwf.panda.org/about_our_earth/all_publications/lpr_2016/(accessed 25 February 2020).

5. Ripple W. World scientists' warning to humanity: a second notice. BioScience, 2017, vol. 67, no. 12, pp. 1026-1028. Available at: http://dx.doi.org/10.1093/biosci/bix125 (accessed 25 February 2020).

6. Waters C. The Anthropocene is functionally and stratigraphically distinct from the Holocene. Science, 2016, vol. 351, Iss. 6269. Available at: https://science.sciencemag.org/content/351/6269/aad2622 (accessed 25 February 2020).

7. Turkulets S.E., Turkulets A.V., Anikeeva N.S. Formirovanie ekologicheskogo soznaniya v kontekste razvitiya natsionalnogo samosoznaniya rossiyan [The formation of environmental awareness in the context of the development of national identity of Russians]. Vlast $i$ upravlenie na Vostoke Rossii, 2017, no. 1 (78), pp. 132-137.

8. Strumse E. The ecological self: a psychological perspective on anthropogenic environmental change. European Journal of Science and Theology, 2007, vol. 3, no. 2, pp. 7-12.

9. Raus R. Student teacher ecological self in the context of education for sustainable development: a longitudinal case study. Journal of Education for Sustainable Development, 2017, no. 11 (2), pp. 123-140. DOI: $10.1177 / 0973408218779283$

10. Mdivani M.O., Khisambeev Sh.R. Ekologicheskoe samosoznanie kak osnova proekologicheskogo povedeniya [Environmental self-awareness as the basis of pro-environmental behavior]. Azimut nauchnykh issledovaniy: pedagogika i psikhologiya, 2017, vol. 6, no. 4 (21), pp. 346-348.

11. Education at a Glance 2018: OECD Indicators. 2018, 460 p. Available at: https://www.oecdilibrary.org/education/education-at-a-glance-2018_eag-2018-en (accessed 25 February 2020).

12. Nedospasova O.P., Barysheva G.A., Kayda A.Yu. Sotsialnye eksternalii obrazovatelnykh investitsiy: opyt stran OESR [Social externalities of educational investment: OECD experience]. Nacionalnye interesy: prioritety i bezopasnost, 2019, vol. 15, no. 4 (373), pp. 629-647.

13. The Global Human Capital Report 2017. Preparing people for the future of work. Available at: http://www3.weforum.org/docs/WEF_Global_Human_Capital_Report_2017.pdf (accessed 01 Mach 2020)

14. Ivankina L.I., Latygovskaya T.P. Sotsialnoe upravlenie v usloviyakh nestabilnosti sovremennogo mira [Social management in the conditions of instability of the modern world]. Tomsk, STT Publ., 2013. $200 \mathrm{p}$.

15. Environment at a Glance 2020. Available at: https://doi.org/10.1787/4ea7d35f-en (accessed 1 March 2020).

16. Bronnikova E. S Van Gogom bez musora: tomskiy biznesmen sozdal dvizhenie o razdelenii otkhodov [With Van Gogh without garbage: Tomsk businessman created a waste separation movement]. Available at: https://tv2.today/News/S-van-gogom-bez-musora-tomskiy-biznesmen-organizuet-dvizhenie-o-razdeleniiothodov\#ixzz6GfV69bN2https://tv2.today/News/S-van-gogom-bez-musora-tomskiy-biznesmen-organizuetdvizhenie-o-razdelenii-othodov\#ixzz6E5hYNTXe (accessed 15 Mach 2020).

17. Amirova N.R., Sargina L.V., Frolova A.S. Razvitie ekologicheskogo trenda na sovremennom rynke tovarov i uslug [The development of the environmental trend in the modern market of goods and services]. CITISE, 2019, no. 5, pp. 277-291.

18. Zabolotnov A.Yu. Perspektivy razvitiya ekologicheskogo samosoznaniya v Rossii [Prospects for the development of environmental self-awareness in Russia]. Ekonomika i sotsium, 2015, no. 1-3 (14), pp. $138-142$.

19. Barysheva G.A., Klemasheva E.I., Malanina V.A., Monastyrny E.A., Nedospasova O.P., Pavlova I.A., Frolova E.A. Aktivnoe blagopoluchie starshego pokoleniya: dolgoletie $i$ vovlechennost v regionalny sotsium [Active well-being of the senior generation: longevity and involvement in the regional society]. Tomsk, STT Publ., 2019. 136 p.

20. Frolova E.A., Kashapova E.R., Klemasheva E.I., Malanina V.A. Comparative analysis of social and demographic characteristics of the older adults in Russia. Journal of Wellbeing technologies, 2019, no. 4 (35), pp. 54-62. Available at: http://jwt.su/journal/article/view/995/1016 (accessed 1 March 2020). In Rus.

Received: 17 March 2020. 